\title{
Editorial
}

\section{Control of Power Converters for Emerging Applications of Power Electronics}

\author{
Ahmed M. Massoud, ${ }^{1}$ Shehab Ahmed, ${ }^{2}$ Ayman S. Abdel-Khalik, ${ }^{2,3}$ \\ Ahmed A. Elserougi, ${ }^{2,3}$ and Khaled H. Ahmed ${ }^{4}$ \\ ${ }^{1}$ Department of Electrical Engineering, Qatar University, Doha, Qatar \\ ${ }^{2}$ Electrical and Computer Engineering Department, Texas A\&M at Qatar, Doha, Qatar \\ ${ }^{3}$ Department of Electrical Engineering, Alexandria University, Alexandria 21526, Egypt \\ ${ }^{4}$ Department of Electrical Engineering, Aberdeen University, Aberdeen AB24 3UE, UK
}

Correspondence should be addressed to Ahmed M. Massoud; ahmed.massoud@qu.edu.qa

Received 20 July 2016; Accepted 20 July 2016

Copyright (C) 2016 Ahmed M. Massoud et al. This is an open access article distributed under the Creative Commons Attribution License, which permits unrestricted use, distribution, and reproduction in any medium, provided the original work is properly cited.

With the skyrocketed development in semiconductor devices, power electronics converters, either at system-level or at device-level, are receiving special attention in different applications as renewable energy sources, drive systems, power quality applications, High-Voltage DC (HVDC) transmission, and Flexible AC Transmission Systems (FACTS). Control of power converters plays a significant role in meeting the requirements and standards of the relevant application. For instance, in the grid integration of renewable energy sources, the quality of the injected power is of paramount importance where the control is the key player. In drive system applications, the robustness and high dynamic performance are a typical demand. Moreover, control of power converters is the workhorse for energy management in other applications (e.g., energy storage systems, solid state transformers, and electric vehicles). The requirements of the control form a sort of consortium with power electronics meshing towards the compliance with the application main needs.

The main purpose of this special issue is to publish highquality research papers as well as review articles addressing recent advances on control for emerging topics in power electronics.

Control of power converters for emerging applications of power electronics has been addressed extensively in literature [1-7] covering the following main areas: control of DC-AC converters for different applications (e.g., grid integration, power quality enhancement, FACTS devices, and HVDC systems); control of DC-DC converters for different applications (e.g., electric vehicles, DC-DC transformers); control of AC-DC converters for different applications (e.g., renewable energy sources, drive systems, FACTS devices, and HVDC systems); control of AC-AC converters for different applications (e.g., drive systems, solid state transformer); control and management of energy storage systems (e.g., batteries, super capacitors, and flywheels); and control of AC drive systems (e.g., induction machines, permanent magnet machines, and multiphase machines).

Many manuscripts have been submitted to this special call spanning different areas. A brief overview of each manuscript selected for this special issue is presented in the following part.

B. Yuan et al. present in their paper an improved PhaseLocked-Loop (PLL) control with alternative damping factors for Voltage Source Converter (VSC) connected to weak AC grids where the gains of the PLL have significant impacts on the power transfer limits. First, the authors prove that the impedance angle of AC system has a significant impact on the small-signal stability of the VSC where, with the same variation tendency of Thévenin equivalent resistance, the limits of power transmission are changing in opposite trends for rectifier and inverter. Second, the improved PLL 
with alternative damping factors is proposed based on the participation factor analysis. Third, the optimal damping factors of the improved PLL control for rectifier and inverter are calculated. Simulations and calculations are presented to validate the following three conclusions:

(i) In rectifying operation, the equivalent system resistance has a negative impact on the stability of the system and this is not the case for inverting operation.

(ii) Adding the alternative damping factors to PLL control shows similar results compared with changing the impedance angle of the AC system.

(iii) The proposed optimal damping factors of PLL can effectively extend the power transfer limits under both rectifier and inverter modes.

Q. Zhang et al. present in their paper a simple and efficient rule-based energy management system of experimental battery/supercapacitor hybrid energy storage system for electric vehicles. The main objective of the proposed energy management system is to utilize the supercapacitor characteristics and to increase the battery lifetime and system efficiency. The role of the energy management system is oriented towards battery reference current, which is subsequently used by the controller of the DC/DC converter. First, a current controller is designed to realize load current distribution between battery and supercapacitor. Then a voltage controller is designed to ensure that the supercapacitor SOC fluctuates within a preset reasonable variation range. An experimental platform is developed to verify the proposed control concept. In addition, the energy efficiency and the cost analysis of the hybrid system are carried out based on the experimental results to explore the most cost-effective tradeoff.

High-voltage gain power converters are crucial in photovoltaic (PV) power generation due mainly to the low output voltage of PV arrays and the safety concerns. J.-G. Mũnoz et al. present in their paper performance analysis of a peak-current mode control with compensation ramp for a boost-flyback power converter. The closed-loop analysis is performed where the converter is considered as a piecewise linear system, and the closed-loop stability is determined. To avoid overcompensation effects, the minimum value required by the compensation ramp is obtained, and the minimum and maximum values of the load resistance are found too. The system has a good transient response under disturbances in both the load and the input voltage.

Y. Wang et al. present in their paper an improved Maximum Power Point Tracking (MPPT) algorithm for PV generation applications based on $P-U$ curve reconstitution especially due to the fact that the $P$ - $U$ curve changes dynamically with the change of irradiance and temperature. The mathematical model of the PV array is presented, and then the output dynamic characteristics are analyzed. Based on this, a $P-U$ curve reconstitution strategy is introduced, and the improved MPPT algorithm is proposed. Simulation and comparative analysis are conducted. Results show that, with the proposed algorithm, MPP is tracked accurately, and the misjudgment problem is solved effectively.
Y. Wang et al. present in their paper a PMSM rotor position detection based on hybrid optical encoder and R-Signal zero-setting scheme; particularly rotor position detection is a prerequisite for achieving good control performance of PMSM and it is difficult to detect rotor position and achieve R-Signal zero-setting. This encoder can do absolute and incremental rotor position detection simultaneously; here, the former is used for acquiring imprecise rotor position and the latter is for precise rotor position. Two detection methods of the encoder are analyzed, and a scheme for rotor position detection is proposed: absolute rotor position is used for motor starting before achieving R-Signal zero-setting; once R-Signal zero-setting is achieved, incremental rotor position detection that has high-precision is adopted. Then a scheme for R-Signal zero-setting is proposed. Simulation is conducted, and results show that rotor position detection and R-Signal zero-setting can be achieved by the proposed scheme.

\author{
Ahmed M. Massoud \\ Shehab Ahmed \\ Ayman S. Abdel-Khalik \\ Ahmed A. Elserougi \\ Khaled H. Ahmed
}

\section{References}

[1] L. Schirone, F. Celani, and M. Macellari, "Discrete-time control for DC-AC converters based on sliding mode design," IET Power Electronics, vol. 5, no. 6, pp. 833-840, 2012.

[2] A. Tani, M. B. Camara, B. Dakyo, and Y. Azzouz, "DC/DC and $\mathrm{DC} / \mathrm{AC}$ converters control for hybrid electric vehicles energy management-ultracapacitors and fuel cell," IEEE Transactions on Industrial Informatics, vol. 9, no. 2, pp. 686-696, 2013.

[3] J. Rocabert, A. Luna, F. Blaabjerg, and P. Rodríguez, "Control of power converters in AC microgrids," IEEE Transactions on Power Electronics, vol. 27, no. 11, pp. 4734-4749, 2012.

[4] D. Y. Qiu, S. C. Yip, H. S.-H. Chung, and S. Y. R. Hui, "On the use of current sensors for the control of power converters," IEEE Transactions on Power Electronics, vol. 18, no. 4, pp. 1047-1055, 2003.

[5] R. P. Aguilera and D. E. Quevedo, "Predictive control of power converters: designs with guaranteed performance," IEEE Transactions on Industrial Informatics, vol. 11, no. 1, pp. 53-63, 2015.

[6] R. Majumder, A. Ghosh, G. Ledwich, and F. Zare, "Power management and power flow control with back-to-back converters in a utility connected microgrid," IEEE Transactions on Power Systems, vol. 25, no. 2, pp. 821-834, 2010.

[7] T. G. Habetler and R. G. Harley, "Power electronic converter and system control," Proceedings of the IEEE, vol. 89, no. 6, pp. 913925, 2001. 


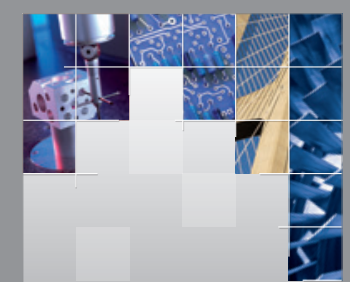

\section{Enfincering}
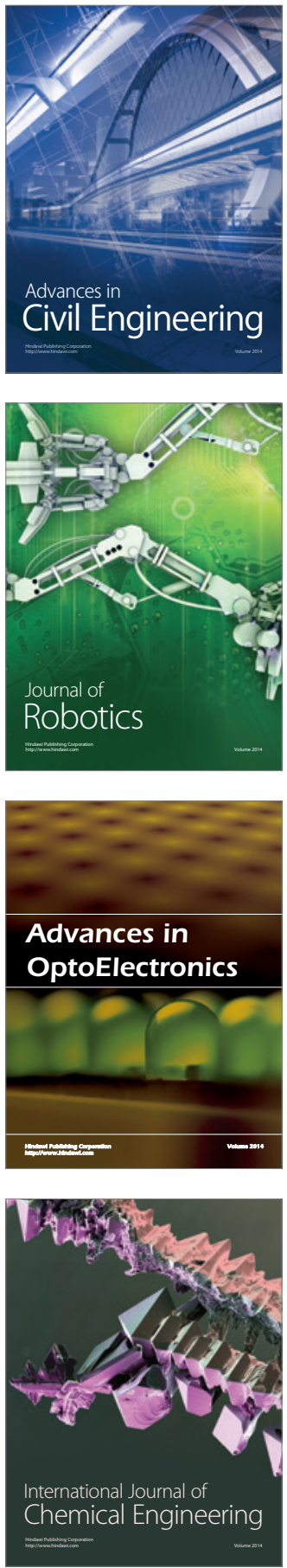

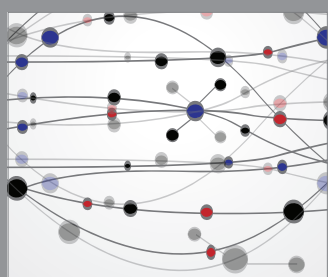

The Scientific World Journal

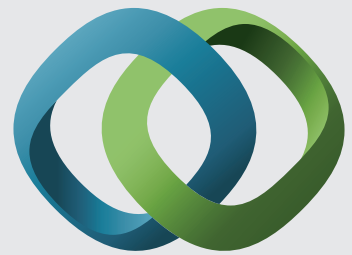

\section{Hindawi}

Submit your manuscripts at

http://www.hindawi.com
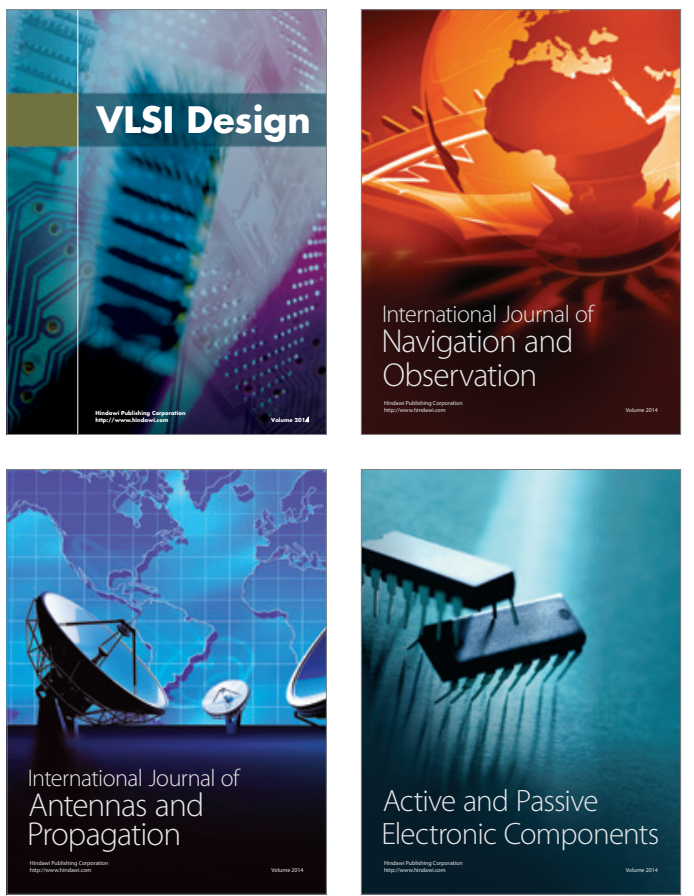
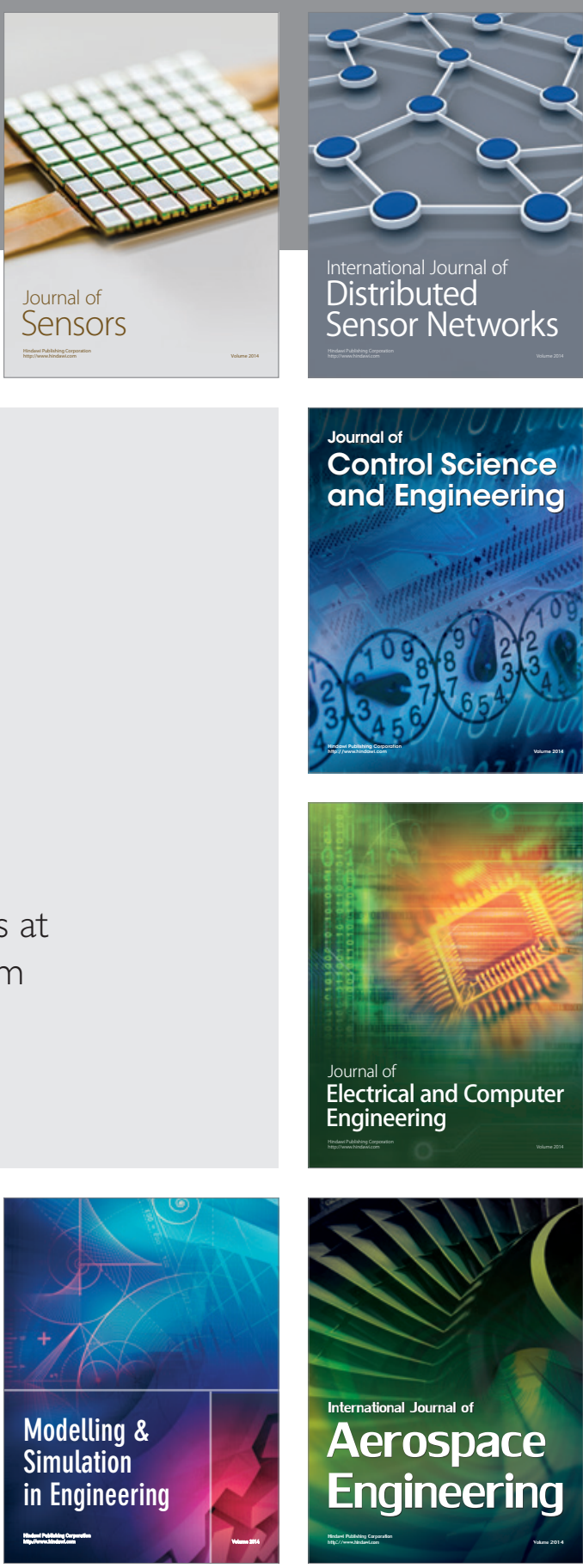

International Journal of

Distributed

Sensor Networks

Journal of

Control Science

and Engineering
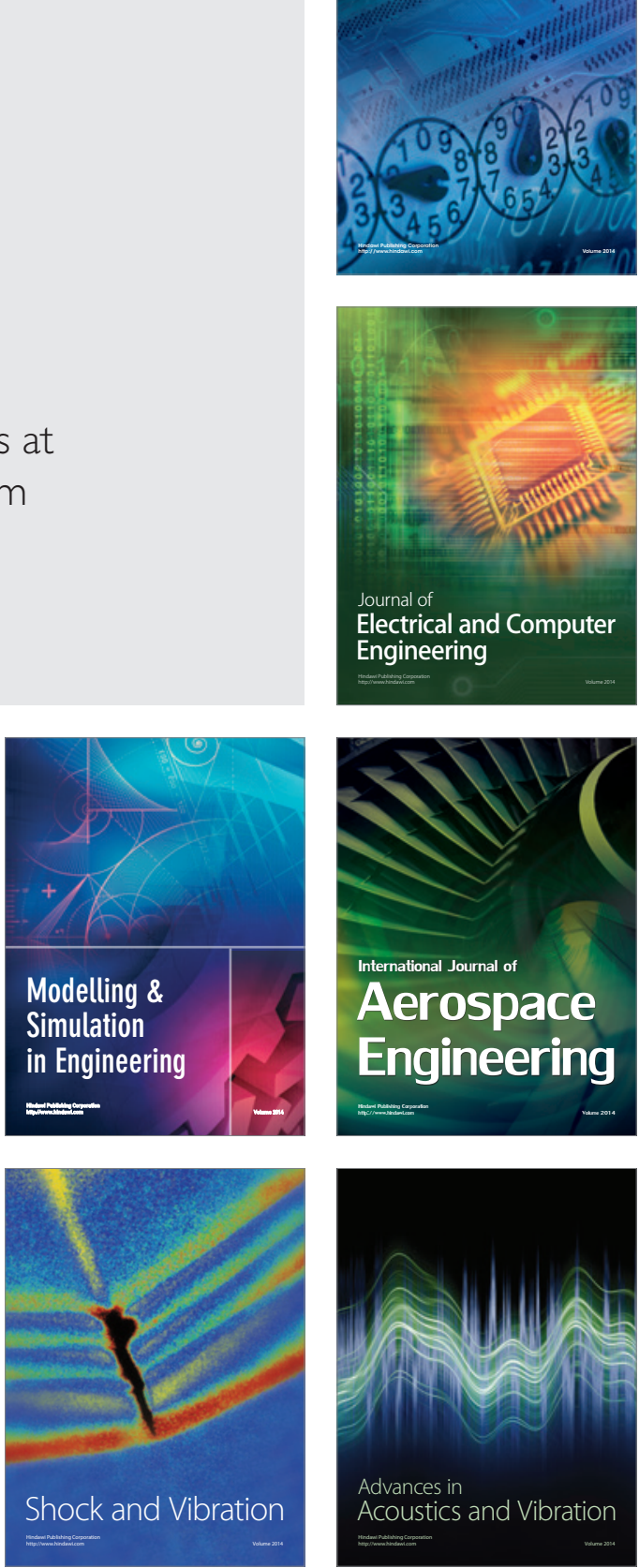